\title{
FLOODED AREA EXTRACTION OF RICE PADDY FIELD IN INDONESIA USING SENTINEL-1 SAR DATA
}

\author{
H. Wakabayashi ${ }^{1}$, K. Motohashi ${ }^{1}$, T. Kitagami ${ }^{2}$, B. Tjahjono ${ }^{3}$, S. Dewayani ${ }^{4}$, D. Hidayat ${ }^{4}$, and C. Hongo ${ }^{2}$ \\ ${ }^{1}$ College of Engineering, Nihon University, Japan - wakabayashi.hiroyuki@nihon-u.ac.jp \\ ${ }^{2}$ Center for Environmental Remote Sensing, Chiba University, Japan \\ ${ }^{3}$ Bogor Agricultural University, Indonesia \\ ${ }^{4}$ Provincial Office of Food Crops and Horticulture of West Java Province, Indonesia
}

Commission III, WG III/2

KEY WORDS: flood, backscattering coefficient, linear discriminant analysis, rice paddy, agricultural insurance

\begin{abstract}
:
The objective of this study is to detect flooded area in rice paddy fields in Indonesia by using remotely sensed data. We used synthetic aperture radar (SAR) data for this purpose, because it is capable of getting high-resolution data in almost all-weather conditions. The paper gives a result of detecting flooded area occurred in our research sites located close to Bandung area, Tegalluar in Bojongsoang district, from the end of February to the beginning of March in 2018. The C-band SAR data acquired by Sentinel-1 were used for this analysis. We derived the gamma-naught threshold for dividing flood and non-flood areas by using a linear discriminant analysis. Discriminant accuracy reached $98 \%$ using VV polarization. By using the gamma-naught threshold and rice paddy field mask (GIS data), the rice paddy flooded area could be extracted with good accuracy.
\end{abstract}

\section{INTRODUCTION}

Indonesia is one of the leading rice producing countries in the world. Rain plays an important role in rice production especially in the area having clear dry and rainy seasons in the Asian tropical region. On the other hand, the changes in precipitation caused by recent climate change have led to damages in agricultural crops due to natural disasters such as droughts and floods. Since droughts and floods have caused damages in rice paddy fields every year, the trials of the agricultural insurances have started to cover rice paddy damages in Indonesia. So far, the evaluation of the rice paddy damage is carried out by the experts' field survey. However, new methods for the damage evaluations by using remotely sensed data are being investigated in our SATREPS project. This project is titled "development and implementation of new damage assessment process in agricultural insurance as adaptation to climate change for food security". The period of this project is from 2017 to 2022 (Hongo and Baba, 2017).

The objective of this study is to extract flooded area in rice paddy fields in Indonesia by using remotely sensed data. We use synthetic aperture radar (SAR) data for this purpose, because it is capable of getting high-resolution data in almost all-weather conditions. The paper gives a result of extracting flooded area occurred at our research sites located close to Bandung area from the end of February to the beginning of March in 2018. The C-band SAR data acquired by Sentinel-1 is used for extracting flooded area in this analysis. The UAV data as well as the ground photos were used for verifying the extracted result.

\section{TEST SITE AND SAR DATA}

\subsection{Test site}

Our test site in this research is Bojongsoang district that is located about $4 \mathrm{~km}$ south east of Bandung City in West Java province. The south of Bojongsoang is surrounded by Citarum River and flooding at paddy fields occurs every year in rainy season from December to March. The flood was occurred in the rice paddy fields in Tegalluar area located in the east part of Bojongsoang during the period from the end of February to the beginning of March in 2018. Figure 1 shows a land use map in Bojongsoang created by the Bogor Agricultural University (Hanidya, 2018). We can recognize that $63 \%$ of land area is used as rice paddy fields followed by settlements, buildings and residential areas. Figure 2 gives a series of false-coloured images covering Tegalluar area taken by PLANET satellites during the period from Feb. 21 to Mar. 4 in 2018. The interval of the images was 2 days and we could recognize the flooded area in each image. The flooding was occurred on Feb. 21 in the center of Tegalluar and expanded till Feb. 27, which reached the maximum flooded area. The area of flood decreased after March.

\subsection{SAR data}

We used Sentinel-1 C-band SAR data for the detection of flooded area in the rice paddy fields, because it is capable of getting relatively high-resolution data in almost all-weather conditions. The characteristics of the Sentinel-1's C-band SAR data are given in Table 1. The SAR data used in this research were acquired in the Interferometric Wide (IW) swath mode. This mode employs the Terrain Observation with Progressive Scans SAR (TOPSAR) technique to acquire data over a wider area using three sub-swaths. The IW mode acquires data over a $250-\mathrm{km}$ swath with a 5 -meter (range) by 20 -meter (azimuth) spatial resolution. The incidence angle of IW mode is from 29 to $46^{\circ}$. The incidence angle at our test site was about 43 degrees. The VV- and VH- polarization data were used in this study. Level-1 Ground Range Detected (GRD) data were downloaded from the European Space Agency (ESA) Copernicus Open Access Hub and input into the Sentinel Toolbox software (ESA, 2018) for further analysis. The SAR data were firstly calibrated to backscattering coefficients and then transformed onto the UTM coordinates. The pixel spacing on the UTM coordinates was set to 10 -meter by 10 -meter. Corrections for the foreshortening as well as the local incidence angle (Terrain Flattening) were applied, because the analysed areas were 
located in the average altitude of $700 \mathrm{~m}$ and the local incidence angle at the observation target was varied in wide swath mode.

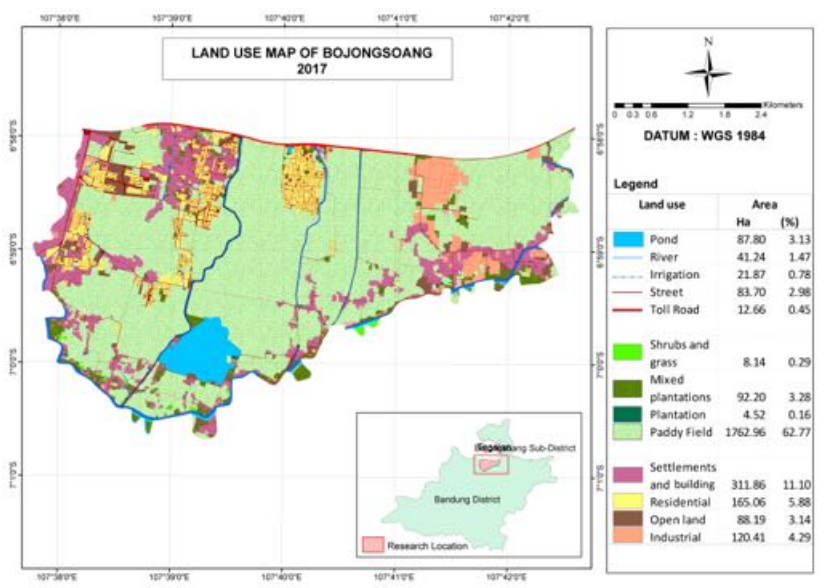

Figure 1. Land use map of Bojongsoang created by Bogor Agricultural University (IPB).
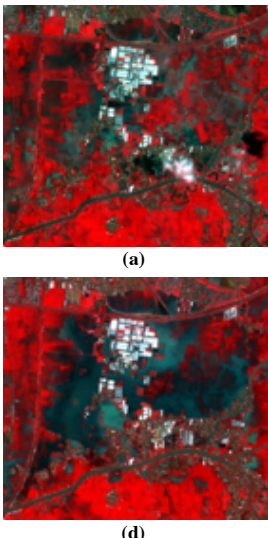

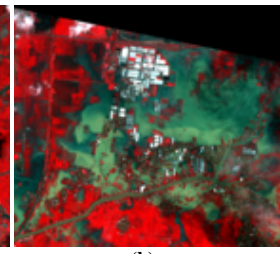

(b)

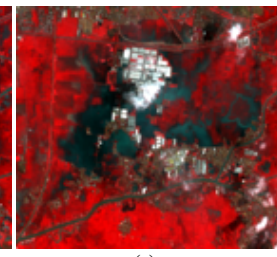

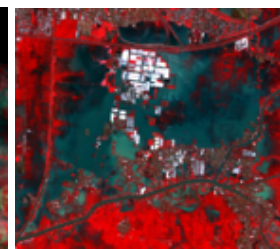

(c)

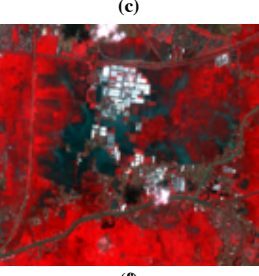

Figure 2. PLANET images covering Tegalluar area in east Bojongsoang acquired from Feb. 21 to Mar. 4 in 2018. (a) Feb.21, 2018, (b) Feb.23, 2018, (c) Feb.25, 2018, (d) Feb.27, 2018, (e) Mar.02, 2018, and (f) Mar.04, 2018.

Table 1. Sentinel-1's C-band SAR characteristics

\begin{tabular}{|c|c|}
\hline & Sentinel-1A/B \\
\hline Center frequency & $5.405 \mathrm{GHz}$ (C-band) \\
\hline Bandwidth & $10-100 \mathrm{MHz}$ \\
\hline Altitude & $693 \mathrm{~km}$ \\
\hline Image width & $80-410 \mathrm{~km}$ \\
\hline Range resolution & $5 \mathrm{~m}$ \\
\hline Azimuth resolution & $20 \mathrm{~m}$ \\
\hline NE sigma zero & $-22 \mathrm{~dB}$ \\
\hline Incidence angle & $20-47 \mathrm{deg}$. \\
\hline Polarimetry & $\mathrm{HH}+\mathrm{HV} \mathrm{or} \mathrm{VV+VH}$ \\
\hline Tx power & $4.4 \mathrm{KW}$ \\
\hline
\end{tabular}

\section{SAR DATA ANALYSIS FOR FLOOD DETECTION}

\subsection{SAR data pre-processing}

The Sentinel-1's C-band SAR data covering our test site were used in this analysis, which were acquired twice on Feb. 17 and Mar. 1 in 2018. The former data were acquired in non-flooded situation and the latter data were in flooded situation. The
SRTM-1 30-meter DEM was used for the corrections of foreshortening as well as the local incidence angle in order to reduce incidence angle distortions on the SAR data. Our procedure to process SAR data using Sentinel Toolbox are given as follows,

(1) Apply Orbit data

(2) Calibrate SAR data to get Beta-naught

(3) Local incidence angle correction to get gamma-naught using SRTM-1 DEM (Radiometric Terrain Flattening)

(4) Foreshortening correction using SRTM-1 DEM (RangeDoppler Terrain Correction)

(5) Transform onto UTM coordinates

\subsection{Flooded area detection}

Figure 3 shows the change of backscattering mechanisms for rice paddy fields as the water depth increase. As shown in this figure, the SAR backscattering coefficients in both VV and $\mathrm{VH}$ polarizations decrease, when the flood occurs in rice paddy fields. Since the thresholds of backscattering coefficient to divide flood and non-flood areas were successfully applied to the SAR data in various frequencies (Henry et al. 2006, Martinis et al. 2015, and Ohki et al. 2016), this method can be used for the Sentinel-1's C-band SAR data as well.

We quantitatively verified classification accuracy of flood and non-flood areas using multivariate discriminant analysis (Fisher, 1936 and Otsu, 1979). We first determined within-class and between-class variance of two classes, flood and non-flood areas, which were recognized in SAR data acquired on February 17 and March 1. We applied a linear discriminant analysis (LDA) in order to separate flood and non-flood areas by gamma-naught, ultimately determining a threshold separating the two classes. Through LDA, a separation line between two classes can be established.

In order to determine a threshold to divide flood and non-flood areas, the gamma-naught in 30 small sampling points were extracted in both flood (March 1) and non-flood (February 17) data. Figure 4(a) shows the 30 sampling points in Tegalluar area We extracted 540 samples in total, because each point in Figure 4 included 3 by 3 samples. Figure 4(b) and 4(c) give the histograms of $\mathrm{VV}$ and $\mathrm{VH}$ gamma-naught backscattering for both flood and non-flood areas, and Table 2 shows the result of LDA for determining threshold values. From the correlation ratio and the discriminant accuracy in this table, we can conclude that $\mathrm{VV}$ data are superior to $\mathrm{VH}$ data in discriminating flooded area in the rice paddy fields.

The median filter was applied to the gamma-naught image with 3 by 3 pixels moving window in order to reduce speckle noise. Then, the rice paddy field in Figure 1 (Figure 5(a)) is used for masking the gamma-naught images as given in Figure 5(b) and 5(c). After applying the thresholds in Table 2 to the gammanaught images in order to detect flooded area, the differential binary image between flood and non-flood images is shown in Figure 6 . The black area in this figure indicates the rice paddy fields where the backscatter was decreased from Feb.17 to Mar.1.

Figure 7(a) gives the ortho-mosaic image acquired by the UAV on Feb. 27, 2018. This image was created from the images taken by the near-infrared camera mounted on the UAV with $150 \mathrm{~m}$ altitude. It covers about 80 ha of southwest Tegalluar area. The colorized image was assigned near-infrared to Red, and the flooded area is easily recognized in this image. Figure 7 (b) and 7(c) show examples of ground photos taken by the pest observer (damage assessor) in Bojongsoang. The extracted flood area can be verified by the image and photos in Figure 7. 


\subsection{Texture analysis}

We tried to estimate flooded area by using the method other than backscattering based method. We used in particular the Gray-Level Co-occurrence Matrix (GLCM) texture analysis (Haralick et al. 1973) for detecting flooded area. When the flood occurred in rice paddy fields, the backscattering is dominated by specular reflections. Since the variance of texture decreases, the spatial entropy may also decrease.

Figure 8(a) and 8(b) give examples of spatial entropy calculated based on GLCM, in which the number of level is 32 with 5 by 5 window calculating texture at the angle of $0 \mathrm{deg}$. Since the spatial entropy decreases at the flooded area, we may use this method to find the flooded area with SAR data.

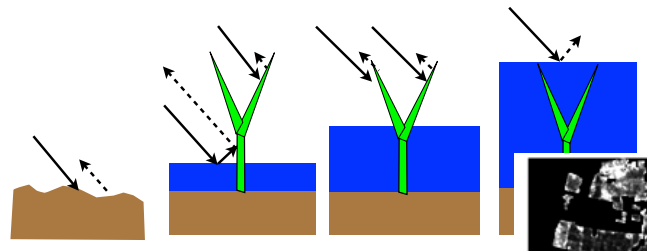

\begin{tabular}{|c|c|c|c|c|}
\hline Paddy status & Before planting & Irrigation & Increase water level & Completely flood \\
\hline Dominant scattering & $\begin{array}{c}\text { Surface scattering from } \\
\text { the ground }\end{array}$ & $\begin{array}{c}\text { Volume scattering+ } \\
\text { Double bounce }\end{array}$ & Volume scattering & Specular scattering \\
\hline $\begin{array}{c}\text { Change of } \\
\text { backscattring }\end{array}$ & & increase & decrease & decrease \\
\hline
\end{tabular}

Figure 3. Change of backscattering mechanisms of rice paddy fields.

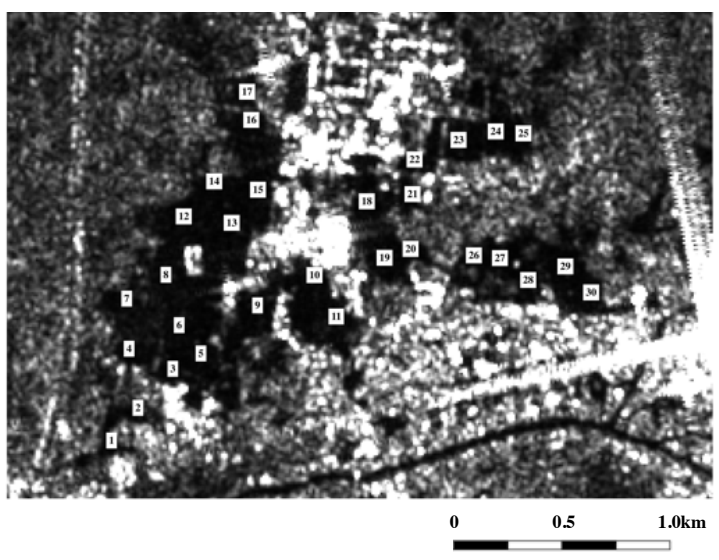

(a)

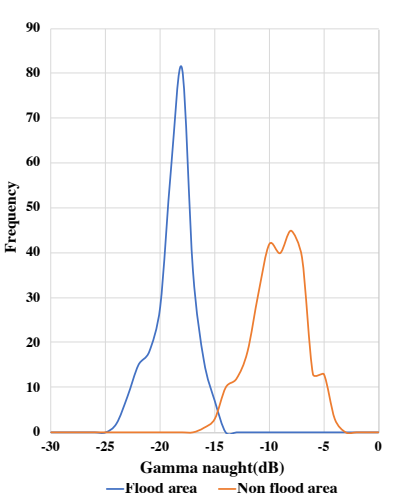

(b)

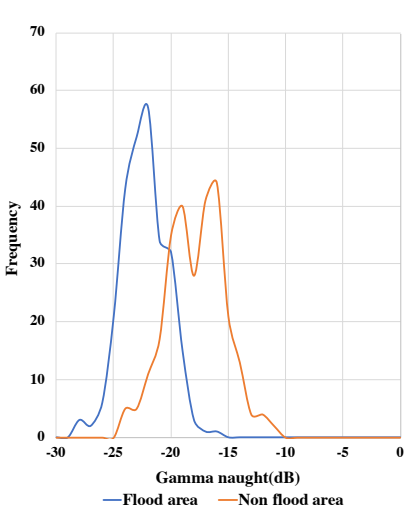

(c)
Figure 4. Gamma-naught distributions for both flood and nonflood rice paddy fields. (a) 30 sampling points in Tegalluar area, (b) VV gamma-naught and (c) VH gamma-naught distributions in both flood and non-flood rice paddy fields.
Table 2. Result of linear discriminant analysis for determining gamma-naught thresholds.

\begin{tabular}{|c|c|c|c|}
\hline Polarization & Threshold(dB) & Correlation ratio & Discriminant accuracy \\
\hline VV & -14.0 & 0.84 & 0.98 \\
\hline VH & -20.1 & 0.49 & 0.83 \\
\hline
\end{tabular}

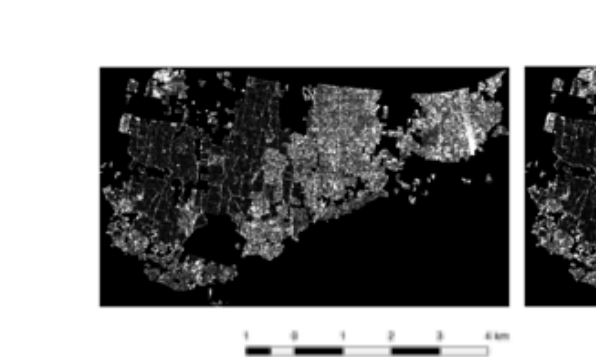

(a)

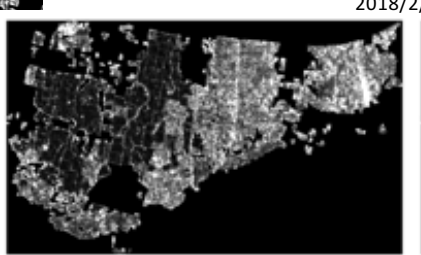

(b)

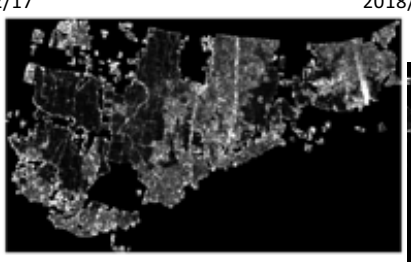

(c)
Figure 5. Figure 6. Gamma-naught images after applying rice paddy field mask. (a) rice paddy field mask, (b) Feb.17,2018, and (c) Mar.1, 2018.

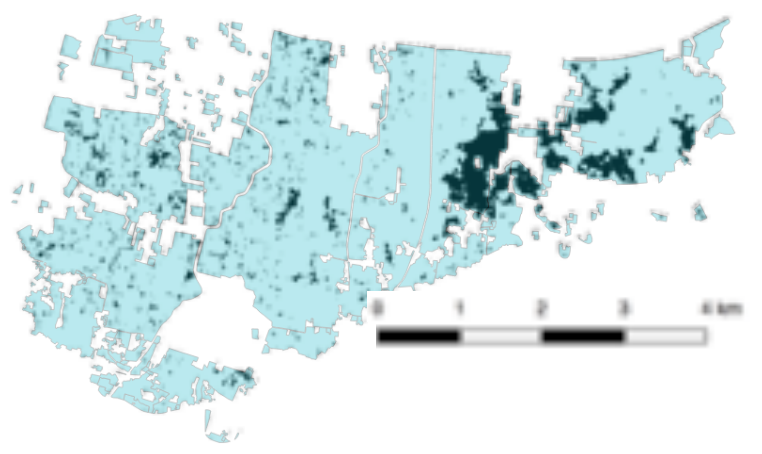

Figure 6. Extracted flooded area from SAR data. Black area indicates the rice paddy fields where the backscattering is decreased from Feb.17 to Mar.1.

\section{SUMMARY}

Agricultural incurrence has been implemented in Indonesia for three years, and the damage assessment of rice paddy is conducted by in-situ observations. We are now investigating new methods to evaluate the damage in rice paddy fields by using remotely sensed data in our SATREPS project. In this paper, we tried to evaluate damage in rice paddy field caused by the flood in Bojongsoang from the end of February to the beginning of March in 2018.

We can conclude that the detection of flood area is possible by using the threshold of C-band SAR gamma-naught with good accuracies. The ortho-mosaic UAV image as well as ground photos taken by pest observer verify the estimated flood area. Since the knowledge of rice paddy growing stage is necessary for accurate damage assessment caused by flooding, we will conduct the further investigation to monitor rice paddy growing stage (Nguyen et al. 2016) combined with our flood detection method. 


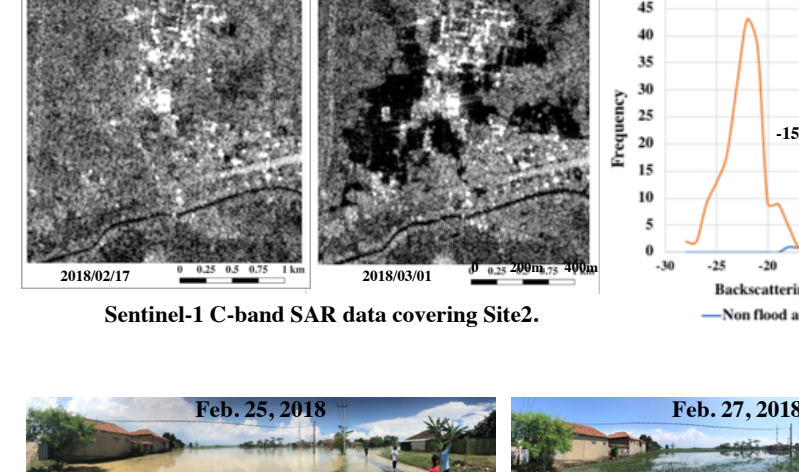

(a)

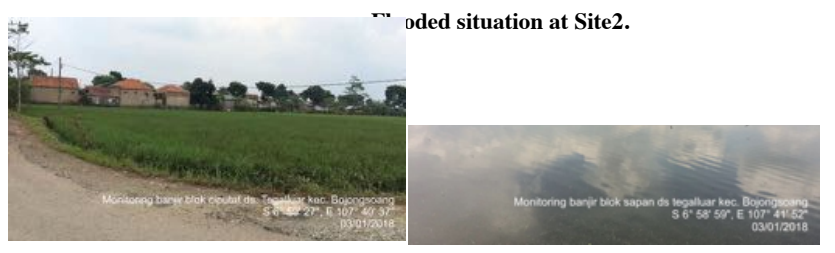

(b)

(c)

Figure 7. Dataset for verifying detected flooded area. (a) Orthomosaic image covering 80-ha of Tegalluar area in Bojongsoang, which was acquired by the UAV mounting the near-infrared camera on Feb.27. (b) and (c) Examples of ground photos taken by the pest observer in Bojongsoang.

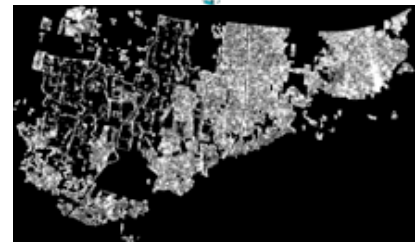

(a)

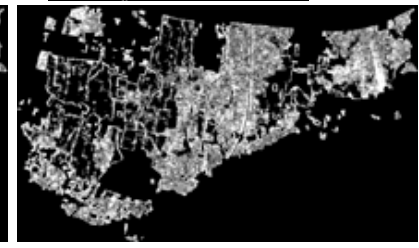

(b)
Figure 8. Examples of spatial entropy image calculated based on GLCM. (a) Feb.17, 2018, and (b) Mar.1, 2018.

\section{ACKNOWLEDGEMENTS}

This work was conducted under the SATREPS project, "Development and Implementation of New Damage Assessment Process in Agricultural Insurance as Adaptation to Climate Change for Food Security". The Sentinel-1 data were provided by the ESA. This research has been partly conducted by the cooperative research with Center for Environmental Remote Sensing, Chiba University. We are grateful to the pest observers for their fieldwork at Bojongsoang. We also thank Sella Atika Sri Kumala, Farah Satira Hanidya, and Yuki Watanabe for their works making and analyzing GIS data in Bojongsoang.

\section{REFERENCES}

Hongo, C, and Baba, B.,2017. SATREPS Project. https://www.jst.go.jp/global/english/kadai/h2804_indonesia.htm 1

Hanidya, F. S., 2018. Flood Vulnerability Analysis in Bojongsoang District, Bandung Regency, Graduation Research of Land Resource Management Study Program, Bogor Agricultural University (IPB).
ESA Sentinel toolbox develop team: https://sentinel.esa.int/web/sentinel/toolboxes

Henry, J. B., Chastanet, P., Fellah, K. ,and Desnos ,Y. L., 2006. Envisat multi-polarized ASAR data for flood mapping, International Journal of Remote Sensing, Vol. 27, No. 10, pp.1921-1929.

Martinis, S., Kersten, J., and Twele, A., 2015. A fully automated TerraSAR-X based flood service, ISPRS Journal of Photogrammetry and Remote Sensing 104, pp.203-212.

Ohki, M., Watanabe, M., Natsuaki, R., Motohka, T., Nagai, H., Tadono, T., Suzuki, S., Ishii, K., Itoh, T., Yamanoguchi, T. and Shimada, M., 2016. Flood Area Detection Using ALOS-2 PALSAR-2 Data for the 2015 Heavy Rainfall Disaster in the Kanto and Tohoku Area, Japan, Journal of The Remote Sensing Society of Japan, Vol.36, No.4, pp.348-359.

Fisher, R.A., 1936. Annals of Eugenics 7(2) : The use of multiple measurements in taxonomic problems, lackwell Publishing Ltd, University College London, pp. 179-188.

Otsu, N., 1979. A Threshold Selection Method from Gray-Level Histogram, IEEE Trans. on System Man Cybernetics, SMC, Vol,9(I), pp. 62-66.

Haralick, R.M., Shanmugam, K., and Dinstein, I., 1973. Texture Features for Image Classification, IEEE Trans. on Systems, Man and Cybernetics, Vo. 3, No. 6, pp. 610-621.

Nguyen, D. B., Gruber, A., and Wagner, W., 2016. Mapping rice extent and cropping scheme in the Mekong Delta using Sentinel-1A data, Remote Sensing Letters, Vol. 7, No.12, pp. 1209-1218. 